\section{PENERAPAN SISTEM INFORMASI ACCURATE VERSI 5 TERHADAP PENYUSUNAN LAPORAN KEUANGAN (Studi Kasus Pada CV Percetakan Karya)}

\author{
Muhammad Azhar Riyadi dan Abdul Rouf \\ Program Studi Akuntansi, Institut Bisnis dan Informatika Kesatuan \\ Bogor, Indonesia \\ Email:lemlit@stiekesatuan.ac.id
}

Penerapan Sistem

Informasi

Accurate Versi 5 terhadap

Penyusunan Laporan

Keuangan (Studi

Kasus Pada CV

Percetakan

Karya)

\section{ABSTRACT}

Such rapid development in the business world, especially for SMEs, will greatly strengthen competitiveness between the scale of the company. The business development must be a concern for business owners to improve the quality of their business. The company must process the data resulting from its business operations into valuable information for quick and accurate decision making, in order to know how the business development is able to compete or not with its competitors. Information technology is said to help SMEs in providing the infrastructure needed to provide the right information for their users. The purpose of this research is to see how accurate program help business owners in preparing financial statements. This type of research is a qualitative descriptive type by conducting observations and interviews directly to CV Percetakan Karya.

The result of this study shows that the accurate program can make easier to compile CV Percetakan Karya financial statements, the resulting report in the form of income statement and balance sheet report. The accurate program also makes easier fo $C V$ Percetakan Karya to entry transaction data into the accurate program. The accurate program can provide detailed and complete financial statements, so companies can easily analyze the financial statements.

Keyword: Accurate Information system, Financial Statement

\section{PENDAHULUAN}

Sejak tahun 2008 - 2013 usaha mikro, kecil dan menengah mengalami perkembangan, jumlah usaha mikro, kecil dan menengah rata-rata mencapai sebesar $2,41 \%$. Pada tahun 2013 jumlah usaha mikro, kecil dan menengah sudah mencapai 57.895.721 unit dan total usaha mikro, kecil dan menengah beserta usaha besar mencapai 57.900.787 unit (Kementrian Koperasi dan UKM, 2017). Demikian juga terhadap perkembangan penerbitan izin usaha mikro dan kecil (IUMK) sampai dengan periode April 2017 di Indonesia dengan wilayah yang paling banyak dalam penerbitan IUMK yaitu wilayah Jawa Tengah pada posisi pertama, Sulawesi Selatan posisi kedua, dan diikuti Nusa Tenggara Barat pada posisi ketiga yang masing-masing berjumlah sekitar 39.000, 30.000 dan 22.000 unit yang sudah menerbitkan izin usaha mikro dan kecil (IUMK) (Kementerian Koperasi dan UKM). Berdasarkan data yang diperoleh dari website resmi Kementrian Koperasi, usaha mikro, kecil dan menengah telah menyumbang Produk Domestik Bruto (PDB) atas dasar harga berlaku sebesar 60,34\% atau sebesar Rp 5.440.007.900.

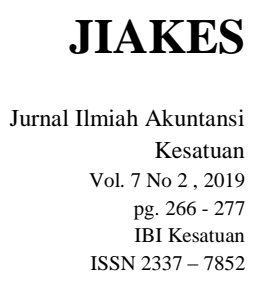


Penerapan

Sistem Informasi

Accurate Versi 5

terhadap

Penyusunan

Laporan

Keuangan (Studi

Kasus Pada CV

Percetakan

Karya)

267
Perkembangan usaha tersebut, harus menjadi perhatian bagi pemilik usaha untuk meningkatkan kualitas dari usaha yang dijalaninya agar mampu bersaing dengan Global di perdagangan bebas antar negara-negara Asean (MEA). Perusahaan harus mengolah datadata hasil operasi usahanya menjadi sebuah informasi yang sangat berharga untuk pengambilan keputusan yang cepat dan akurat bagi internal perusahaan atau pemilik usaha serta pihak eksternal yang memiliki kepentingan dengan perusahaan tersebut, agar dapat mengetahui bagaimana perkembangan usaha tersebut, apakah mampu bersaing atau tidak dengan kompetitornya. Teknologi modern sangat mengurangi biaya informasi dan kapabilitas untuk berpartisipasi dalam ekonomi global. Pada kenyataannya, terdapat cukup bukti bahwa small medium enterprises tidak hanya dikembangkan di sektor ekonomi domestik, tetapi keberadaannya di internasional memiliki pertumbuhan yang baik (Char, Yasoa dan Hassan, 2010).

Sistem informasi akuntansi yang disusun sebenarnya dapat diproses secara manual atau secara komputerisasi namun karena perkembangan teknologi informasi yang semakin canggih, dewasa ini telah mendorong semakin majunya teknologi komputer. Penggunaan teknologi informasi secara signifikan telah mempengaruhi praktik akuntansi dan keuangan, telah banyak pergantian olah data akuntansi manual ke sistem akuntansi yang menggunakan komputer, dengan software akuntansi seperti Accurate Accounting dan program sejenis lainnya yang bisa dipilih sesuai dengan jenis usahanya atau lokasi usahanya (Yuliana dan Triandi, 2013). Menurut (Baig dan Gururajan, 2011), teknologi informasi merupakan salah satu sarana untuk meningkatkan kinerja perusahaan dan bisnis. Akuntansi sebagai bisnis, sistem bahasa dan informasi, harus menyesuaikan diri dengan teknologi baru yang akan disampaikan kepada pengguna laporan keuangan (Sarokolaei $e t$ al., 2012). Teknologi informasi dikatakan dapat membantu UKM dalam menyediakan infrastruktur yang diperlukan untuk menyediakan informasi yang tepat bagi penggunanya (Ghobakhloo et al., 2012).

Kendala yang ada pada UMKM adalah tidak memiliki laporan keuangan sesuai dengan standar SAK-ETAP dan UMKM yang memiliki catatan keuangan yang baik mempunyai perkembangan yang lebih pesat dibanding UMKM lainnya meskipun usia pendiriannya sama, bahkan lebih muda dari beberapa UMKM yang lainnya (Narsa, Widodo, dan Kurnianto, 2012). Untuk penyusunan laporan tersebut tidak mudah dan harus diketahui kebutuhan apa saja yang harus disediakan dalam tiap tahunnya secara rutin. Seperti yang disyaratkan SAK EMKM yang akan berlaku efektif per 1 januari 2018 menyebutkan bahwa laporan keuangan minimum terdiri dari :

1. Laporan Posisi Keuangan pada akhir periode

2. Laporan Laba Rugi selama periode

3. Catatan Atas Laporan Keuangan, yang berisi tambahan dan rincian pos-pos tertentu yang relevan

Umumnya UMKM yang masih belum mengetahui penggunaan aplikasi penyusunan laporan keuangan terapan menjadi tantangan tersediri untuk dapat memahami seberapa kuat para UMKM dalam mengetahui aplikasi sebagai penunjang dan penyusunan laporan keuangan khususnya aplikasi akuntansi Accurate.

Berdasarkan latar belakang yang ada, permasalahan dalam penelitian ini adalah :

1. Kendala UMKM adalah tidak memiliki laporan keuangan yang sesuai dengan standar SAK-ETAP.

2. Untuk membuat laporan keuangan juga tidak mudah dan perlu memiliki pengetahuan akuntansi serta mengetahui kebutuhan laporan apa saja yang dibutuhkan.

Berdasarkan penjelasan diatas, maka penelitian ini akan difokuskan pada penerapan sistem informasi accurate versi 5 terhadap penyusunan laporan keuangan. 


\section{TINJAUAN PUSTAKA}

Penerapan

Menurut Jensen dan Meckling (1976) hubungan agensi didefinisikan sebagai "Kontrak antara prinsipal dan agen. Proses ini melibatkan pendelegasian sebagian kewenangan pengambilan keputusan kepada agen”. Menurut Jensen dan Meckling (1976) "Jika Prinsipal dan Agen adalah utility maximizers, maka ada kesempatan yang lebih besar untuk setiap pihak untuk memaksimalkan kepentingan sendiri”. Dalam hal ini teori agensi akhirnya banyak menghubungkan dengan permasalahan konflik kepentingan yang mungkin muncul dari hubungan kontraktual dari kedua belah pihak dimana pada hakekatnya keduanya memiliki akuisisi informasi yang berbeda.

Menurut George dan William (1996, 1) Sistem Informasi Akuntansi (SIA) adalah : Kumpulan sumberdaya, seperti manusia dan peralatan, yang diatur untuk mengubah data menjadi informasi. Informasi ini dikomunikasikan kepada beragam pengambil keputusan. Sistem Informasi Akuntansi mewujudkan perubahan ini apakah secara manual atau terkomputerisasi.

Sedangkan menurut Steven $(1981,6)$ dalam Zaki Baridwan, Sistem Informasi Akuntansi adalah : suatu komponen organisasi yang mengumpulkan, menggolongkan, mengolah, menganalisa, dan mengkomunikasikan informasi keuangan yang relevan untuk pengambilan keputusan kepada pihak-pihak luar (seperti inspeksi pajak, investor dan kreditur) dan pihak-pihak dalam (terutama manajemen).

Berdasarkan website resmi milik Cipta Piranti Sejahtera (CPSSoft), program Accurate accounting pertama kali diluncurkan pada tahun 1999 oleh CPSSoft. Dengan visinya yaitu "Meningkatkan UKM di Indonesia menjadi usaha yang berkelas dan dikelola secara professional" jumlah pengguna Accurate telah lebih dari 80.000.

Accurate Versi 5 terdiri dari modul - modul yang dikemas dalam satu paket, terdiri dari :

1. Modul pembelian (Purchase Module) : modul ini terdiri dari Formulir Permintaan Pembelian (Purchase Requisition Form), Formulir Pesanan Pembelian (Purchase Order Form), Formulir Penerimaan Barang (Received Item Form), Formulir Faktur Pembelian (Purchase Invoice Form), Formulir Retur Pembelian (Purchase Return Form) dan Formulir Pembayaran Pembelian (Purchase Payment Form).

2. Modul Penjualan (Sales Module) : modul ini terdiri dari Formulir Penawaran Penjualan (Sales Quotation Form), Formulir Pesanan Penjualan (Sales Order Form), Formulir Faktur Penjualan (Sales Invoice Form), Formulir Retur Penjualan (Sales Return Form) dan Formulir Penerimaan Penjualan (Sales Receipt Form).

3. Modul Persediaan (Inventory Module) : modul ini terdiri dari Daftar Barang dan Jasa (List Of Item), Formulir Penyesuain Persediaan (Inventory Adjustment Form), Formulir Pembiayaan Pesanan (Job Costing Form), Daftar Gudang (List Of Warehouse), Formulir Grup Barang (Item Grouping Form), Formulir Penyesuaian Harga Jual Barang (Set Selling Price Adjustment Form), dan Formulir Pindah Barang (Item Transfer Form).

4. Modul Buku Besar (General Ledger Module) : modul ini terdiri dari Daftar Akun (List Of Account), Daftar Mata Uang (List Of Currency), Informasi Perusahaan (Company Info), Formulir Bukti Jurnal (Journal Voucher Form), Proses Akhir Bulan (Period End Process), dan Laporan Keuangan (Financial Statement). 
Penerapan

Sistem Informasi

Accurate Versi 5

terhadap

Penyusunan

Laporan

Keuangan (Studi

Kasus Pada CV

Percetakan

Karya)

5. Modul Kas Bank (Cash Bank Module) : modul ini terdiri dari Formulir Pembayaran (Payment Form), Formulir Penerimaan (Deposit Form), Buku Bank (Bank Book), Formulir Rekonsiliasi Bank (Bank Reconcile Form).

6. Modul Aktiva Tetap (Fixed Asset Module) : modul ini terdiri dari Formulir Aktiva Tetap Baru (New Fixed Asset Form), Daftar Tipe Aktiva Tetap Pajak (List Of Fiscal Fixed Asset Type), Daftar Tipe Aktiva Tetap (List Of Fixed Asset Type), Daftar Aktiva Tetap (Fixed Asset List).

7. Modul RMA (Return Merchandise Authorization Module) : modul ini terdiri dari Formulir RMA (RMA Form) dan Formulir RMA Action (RMA Action Form).

8. Modul Proyek (Project Module) : modul ini terdiri dari Daftar Bahan Baku, Daftar Biaya Proyek, Formulir Work Price Analysis, Formulir Proyek, Formulir Material In Used, Formulir Project Survey, Formulir Project Bill, Formulir Project Ending.

Menurut PSAK 1 laporan keuangan adalah suatu penyajian tersrtuktur dari posisi keuangan dan kinerja keuangan suatu entitas. Tujuan laporan keuangan adalah sebagai berikut.

1. Tujuan laporan keuangan adalah menyediakan informasi yang menyangkut posisi keuangan, kinerja, serta perubahan posisi keuangan suatu perusahaan yang bermanfaat bagi sejumlah besar pemakai dalam pengambilan keputusan ekonomi.

2. Laporan keuangan yang disusun untuk tujuan ini memenuhi kebutuhan bersama sebagian besar pemakai. Namun demikian, laporan keuangan tidak menyediakan semua informasi yang mungkin dibutuhkan pemakai dalam pengambilan keputusan ekonomi karena secara umum menggambarkan pengaruh keuangan dari kejadian di masa lalu, dan tidak diwajibkan untuk menyediakan informasi nonkeuangan.

3. Laporan keuangan juga menunjukan apa yang telah dilakukan manajemen (stewardship), atau pertanggungjawaban manajemen atas sumber daya yang dipercayakan kepadanya. Pemakai yang ingin menilai apa yang telah dilakukan atau pertanggungjawaban manajemen berbuat demikian agar mereka dapat membuat keputusan ekonomi; keputusan ini mungkin mencakup, misalnya, keputusan untuk menahan atau menjual investasi mereka dalam perusahaan atau keputusan untuk mengangkat kembali atau mengganti manajemen.

\section{METODE PENELITIAN}

Penelitian ini merupakan penelitian kualitatif. Analisis data kualitatif menyangkut identifikasi apa yang menjadi perhatian dan apa yang merupakan permasalahan. Dalam melakukan identifikasi ini ada beberapa proses yang perlu dilakukan menurut Ronny (2007, 192), yaitu:

1. Proses Kategorisasi

2. Proses Prioritas

3. Proses Penentuan Kelengkapan

Jenis dan sumber data yang digunakan dalam penelitian ini adalah : data sekunder dan data primer. Teknik yang digunakan dalam penelitian ini, adalah : wawancara dan pengamatan (observasi). 
Proses bisnis perusahaan ini dimulai dari pemesanan pelanggan, perusahaan hanya menyediakan barang dagangan yang biasanya digunakan oleh percetakan, misalnya bahan kertas jenis tertentu yang banyak digunakan pelanggan. Untuk barang tertentu yang jarang dipesan oleh pelanggan, jika ada pesanan, barang tersebut akan dipesan terlebih dahulu, karena perusahaan harus memesan ke pabrik langsung dan ketika barang sudah ready maka barang tersebut siap untuk dijual kepada pelanggan.

Pesanan pelanggan biasanya diterima melalui telepon atau datang langsung, bagi pelanggan tetap yang sudah sering membeli barang dapat memesan langsung ke bagian marketing, selanjutnya akan langsung dibuatkan faktur penjualan, ketika barang sudah ready. Faktur tersebut dibuat, disimpan, dikumpulkan dan akan dikirimkan ke pelanggan setiap minggunya. Pengiriman barang dilakukan sesuai dengan permintaan pelanggan. Penjualan biasanya meliputi : bahan mentah utuh dari pabrik yang akan dikirim atau diminta oleh pelanggan, namun ada beberapa yang meminta untuk di proses terlebih dahulu, misalnya pelanggan menginginkan bahan kertas yang telah dipotong-potong sebelum dikirim atau dipotong sesuai permintaan maka sebelum dikirim bisa melayani pemotongan bahan dengan menggunakan mesin potong khusus yang dimiliki. Sisa hasil potongan kertas biasanya akan dibawa oleh pelanggan, jika tidak dibawa oleh pelanggan akan dibuang. Pengiriman barang bisa menggunakan mobil box atau motor. Pelanggan yang melakukan pesanan terkadang tidak menggunakan purchase order, dan hal tersebut biasanya hanya untuk pelanggan tetap saja atau pelanggan yang benar-benar sudah dipercaya. Namun beberapa pelanggan biasanya melakukan pemesanan dengan dokumen purchase order menyusul, karena bahan kertas yang dijual, harganya sangat berfluktuasi jadi dokumen purchase order harus menyesuaikan harga yang tertera di faktur. Kenaikan harga bahan baku kertas didasarkan pada tarif dollar yang makin hari semakin tinggi, bahkan untuk harga bahan baku kertas, cenderung terus meningkat sepanjang tahun. Penjualan dan pengiriman meliputi daerah sekitar Tangerang dimana lokasi tempat operasional perusahaan ini berada, meskipun demikian perusahaan tetap bisa melayani pengiriman ke luar daerah Tangerang dengan menggunakan via telepon, dan beberapa kali sudah melakukan pengiriman ke wilayah Purwakarta dan Purbalingga. Perusahaan ini jarang melakukan pemesanan ke luar kota karena biaya pengirimannya yang cukup besar.

Proses pembelian bahan baku percetakan kepada supplier dimulai dengan menanyakan kepada supplier apakah barang yang dibutuhkan tersedia atau tidak, jika tersedia maka barang akan dipesan, kemudian barang dikirmkan satu hingga dua hari kedepan. Namun jika barang yang dibutuhkan tidak tersedia atau membutuhkan proses pemotongan, perusahaan akan diberi memberitahukan berapa lama proses pemotongan yang dibutuhkan agar barang tersebut siap dibeli atau dikirimkan. Pembelian menggunakan purchase order dan faktur tagihan dari supplier diterima setiap satu minggu sekali.

Proses penggajian karyawan, biasanya dibayar setiap bulan dan biayanya tetap kecuali jika karyawan ditugaskan untuk melakukan lembur, maka akan diberi uang lembur. Semua karyawan diberikan fasilitas BPJS.

Proses pelaporan keuangan, dilakukan oleh Consultant Accountant perusahaan. Semua dokumen-dokumen yang dibutuhkan Accountan akan dikirimkan melalui surat elektronik (E-mail) yang dilakukan bulanan untuk melaporkan pajak bulanan. Selain itu dibuatkan juga laporan keuangan yang menggunakan Microsoft Excel, laporan yang dibuat adalah laporan kas masuk dan kas keluar, laporan perhitungan persediaan akhir tahun, karena menurut Consultant Accountan, hanya laporan kas yang dibutuhkan untuk membuat laporan pajak tahunan. Melalui laporan kas masuk dan kas keluar dapat diketahui berapa 
Penerapan

Sistem Informasi Accurate Versi 5

terhadap

Penyusunan

Laporan

Keuangan (Studi

Kasus Pada CV

Percetakan

Karya)

271 keuntungan perusahaan yaitu dengan membandingkan jumlah kas yang masuk dengan kas yang keluar.

Berikut bagan arus (flow chart) untuk prosedur penjualan :
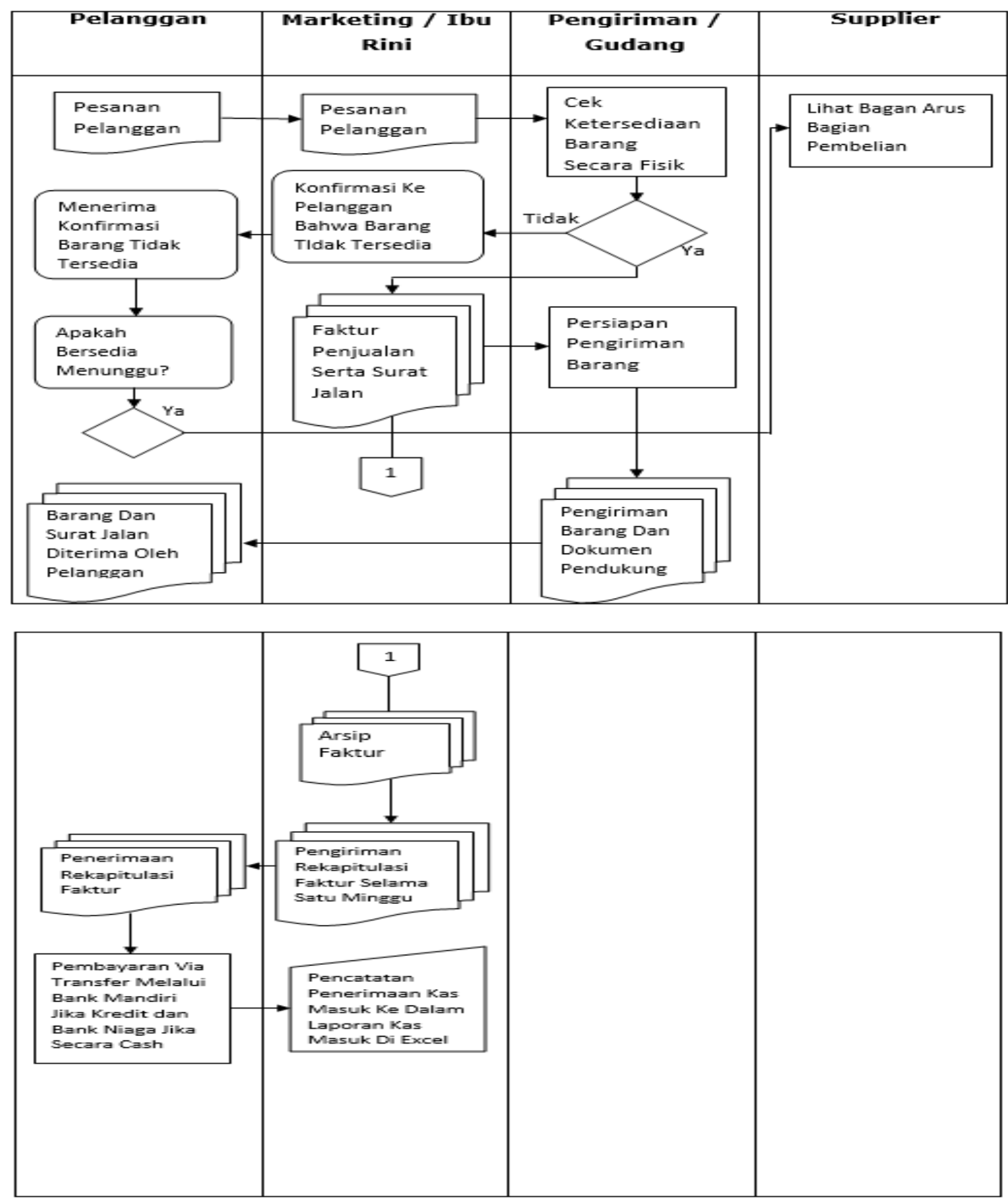

Gambar 1.

Bagan Arus Penjualan 
Berikut bagan arus (flow chart) untuk prosedur pembelian :
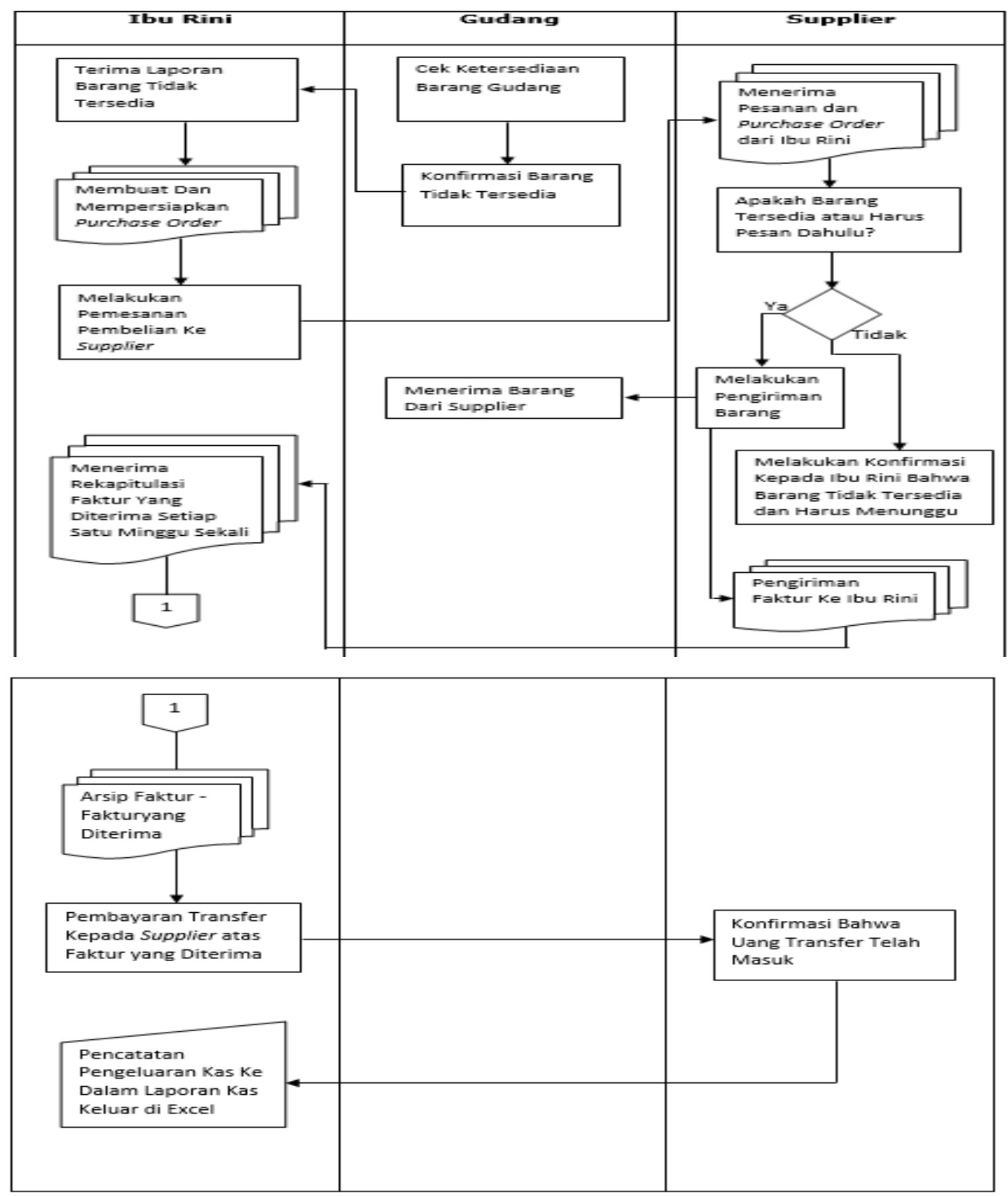

Gambar 2.

Bagan Arus Pembelian
Penerapan

Sistem Informasi

Accurate Versi 5

terhadap

Penyusunan

Laporan

Keuangan (Studi

Kasus Pada CV

Percetakan

Karya)

Setelah melihat bagan arus dari aktivitas bisnis yang dilakukan perusahaan, selanjutnya adalah membuat daftar akun yang disajikan di tabel berikut ini : 
Penerapan

Sistem Informasi

Accurate Versi 5

terhadap

Penyusunan

Laporan

Keuangan (Studi

Kasus Pada CV

Percetakan

Karya)

273
Tabel 1.

Daftar Akun

\begin{tabular}{|l|l|l|}
\hline No Akun & \multicolumn{1}{|c|}{ Nama } & \multicolumn{1}{|c|}{ Tipe } \\
\hline $1101-001$ & Kas & $\begin{array}{l}\text { Kas/Bank } \\
\text { Kas/Bank }\end{array}$ \\
\hline 1102 & Bank & Kas/Bank \\
$1102-001$ & Mandiri IDR & $\begin{array}{l}\text { Kas/Bank } \\
\text { Kas/Bank }\end{array}$ \\
\hline $1102-002$ & Niaga IDR & Akun Piutang \\
$1103-001$ & Piutang Usaha & Akun Piutang \\
\hline 1104 & Persediaan Barang Dagang & Persediaan \\
$1104-001$ & Persediaan Bahan Percetakan & Persediaan \\
\hline 1105 & Biaya Dibayar Dimuka & Aktiva Lancar Lainnya \\
$1105-001$ & Sewa Dibayar Dimuka & Aktiva Lancar Lainnya \\
1106 & PPN Masukan & Aktiva Lancar Lainnya \\
1107 & PPN Lebih Bayar & Aktiva Lancar Lainnya \\
\hline 1201 & Aktiva Tetap & Aktiva Tetap \\
$1201-001$ & Mesin Potong & Aktiva Tetap \\
$1201-002$ & Kendaraan - Mobil Box & Aktiva Tetap \\
$1201-003$ & Kendaraan - Motor & Aktiva Tetap \\
\hline 1202 & Akumulasi Penyusutan & Akumulasi Penyusutan \\
\hline
\end{tabular}

\begin{tabular}{|c|c|c|}
\hline $\begin{array}{l}1202-001 \\
1202-002 \\
1202-003\end{array}$ & $\begin{array}{l}\text { Akum. Penys. Mesin Potong } \\
\text { Akum. Penys. Kendaraan - Mobil Box } \\
\text { Akum. Penys. Kendaraan - Motor }\end{array}$ & $\begin{array}{l}\text { Akumulasi Penyusutan } \\
\text { Akumulasi Penyusutan } \\
\text { Akumulasi Penyusutan }\end{array}$ \\
\hline $\begin{array}{l}2101 \\
2101-001\end{array}$ & $\begin{array}{l}\text { Hutang Usaha } \\
\text { Hutang Usaha }\end{array}$ & $\begin{array}{l}\text { Akun Hutang } \\
\text { Akun Hutang }\end{array}$ \\
\hline $\begin{array}{l}2102 \\
2102-001 \\
2103\end{array}$ & $\begin{array}{l}\text { Uang Muka Penjualan } \\
\text { Uang Muka Penjualan } \\
\text { PPN Keluaran }\end{array}$ & $\begin{array}{l}\text { Akun Hutang } \\
\text { Akun Hutang } \\
\text { Akun Hutang }\end{array}$ \\
\hline $\begin{array}{l}2104 \\
2104-001 \\
2104-002 \\
2105 \\
2106 \\
2201\end{array}$ & $\begin{array}{l}\text { Hutang Biaya } \\
\text { Hutang Bunga } \\
\text { Hutang Gaji } \\
\text { PPN Kurang Bayar } \\
\text { Hutang Lainnya } \\
\text { Hutang Jangka Panjang }\end{array}$ & $\begin{array}{l}\text { Hutang Lancar Lainnya } \\
\text { Hutang Lancar Lainnya } \\
\text { Hutang Lancar Lainnya } \\
\text { Hutang Lancar Lainnya } \\
\text { Hutang Lancar Lainnya } \\
\text { Hutang Jangka Panjang }\end{array}$ \\
\hline $\begin{array}{l}3000 \\
3100\end{array}$ & $\begin{array}{l}\text { Modal } \\
\text { Prive }\end{array}$ & $\begin{array}{l}\text { Ekuitas } \\
\text { Ekuitas }\end{array}$ \\
\hline $\begin{array}{l}4101 \\
4101-001 \\
4101-002\end{array}$ & $\begin{array}{l}\text { Pendapatan } \\
\text { Penjualan Bahan Percetakan } \\
\text { Pendapatan Jasa }\end{array}$ & $\begin{array}{l}\text { Pendapatan } \\
\text { Pendapatan } \\
\text { Pendapatan }\end{array}$ \\
\hline $\begin{array}{l}4201 \\
4201-001 \\
4202\end{array}$ & $\begin{array}{l}\text { Retur Penjualan } \\
\text { Retur Penjualan Bahan Percetakan } \\
\text { Potongan Penjualan }\end{array}$ & $\begin{array}{l}\text { Pendapatan } \\
\text { Pendapatan } \\
\text { Pendapatan }\end{array}$ \\
\hline $\begin{array}{l}5100 \\
5100-001 \\
5200 \\
5300\end{array}$ & $\begin{array}{l}\text { Harga Pokok Penjualan } \\
\text { Hpp Bahan Percetakan } \\
\text { Biaya Angkut Pembelian } \\
\text { Potongan Pembelian }\end{array}$ & $\begin{array}{l}\text { Harga Pokok } \\
\text { Penjualan } \\
\text { Harga Pokok Penjualan } \\
\text { Harga Pokok Penjualan } \\
\text { Harga Pokok Penjualan }\end{array}$ \\
\hline $\begin{array}{l}6100 \\
6100-001 \\
6100-002 \\
6100-003\end{array}$ & $\begin{array}{l}\text { Beban Penyusutan } \\
\text { Beban Penyusutan Mesin Potong } \\
\text { Beban Penyusutan Kendaraan - Mobil Box } \\
\text { Beban Penyusutan Kendaraan - Motor }\end{array}$ & $\begin{array}{l}\text { Beban } \\
\text { Beban } \\
\text { Beban } \\
\text { Beban }\end{array}$ \\
\hline
\end{tabular}




\begin{tabular}{|l|l|l|}
\hline 6200 & Biaya Umum Be Administrasi & Beban \\
$6200-001$ & Biaya listrik \& Telepon & Beban \\
$6200-002$ & Biaya Gaji \& Upah & Beban \\
$6200-003$ & Biaya Sewa & Beban \\
$6200-004$ & Biaya Umum \& Adm Lainnya & Beban \\
$6200-005$ & Biaya Asuransi & Pendapatan Lain \\
7100 & Pendapatan Lain-Lain & Pendapatan Lain \\
$7100-001$ & Pendapatan Bunga Bank & Pendapatan Lain \\
\hline 7200 & Pendapatan Lain-Lain & Beban Lain-Lain \\
$7200-001$ & Biaya Administrasi Bank & Beban Lain-Lain \\
\hline
\end{tabular}

Setelah melakukan analisa proses bisnis dan perancangan sistem, perusahaan baru bisa menerapkan aplikasi Accurate. Data-data yang digunakan adalah data tahun 2017 dan data tahun 2016, dimana data tahun 2016 hanya digunakan sebagai saldo awal tahun 2017. Data yang diperoleh adalah laporan kas masuk, laporan kas keluar, laporan kas, dan daftar persediaan. Pada tahap awal penerapan sistem aplikasi Accurate, dimulai dari persiapan singkat yang terdiri dari pemilihan bahasa, tipe persiapan, mata uang, membuat daftar akun, tipe pelanggan, daftar pelanggan, dan daftar pemasok. Tahap selanjutnya adalah membuat daftar persediaan. Langkah terakhir dalam melakukan set up di persiapan singkat ini adalah mengisi tab bagian aktiva tetap, pada tab aktiva tetap terdapat 3 tab yaitu:

1. Tipe Aset Tetap Kena Pajak

2. Tipe Aset Tetap

3. Daftar Aktiva Tetap

Untuk memasukkan transaksi-transaksi, ada beberapa modul yang digunakan pada aplikasi Accurate versi 5 ini, yaitu modul buku besar, kas bank, persediaan, penjualan, pembelian, aset tetap, RMA, proyek, pabrikasi, dan e-faktur. Untuk membuat faktur penjualan berikut langkah-langkahnya :

1. Buka modul penjualan dan klik faktur penjualan, lalu akan muncul formulir untuk faktur penjualan

2. Masukkan nama pelanggan, nomor faktur, dan tanggal faktur

3. Pilih barang yang akan dijual pada kolom barang

4. Masukkan kuantitas barang yang akan dijual, harga jual, dan kode pajak penjualan yang telah diatur pada persiapan singkat yaitu huruf " $T$ ", maka setelah itu total harga barang akan muncul

5. Klik simpan \& tutup

Berikut langkah-langkah untuk membuat faktur pembelian :

1. Buka modul pembelian dan klik faktur pembelian, sehingga akan muncul formulir faktur pembelian

2. Masukkan nama pemasok, nomor faktur, dan tanggal faktur

3. Pilih barang yang akan dibeli pada kolom barang

4. Masukkan kuantitas barang yang akan dibeli, harga beli per satuan, dan kode pajak, lalu total harga barang akan muncul

5. Klik logo kalkulator untuk menghitung total keseluruhan harga barang

6. Klik simpan \& tutup

Proses trial entri data dilakukan selama dua bulan sampai menghasilkan laporan keuangan, laporan keuangan dicocokkan dengan manual, setelah hasil laporan keuangan sama, sistem dinyatakan siap untuk digunakan. Laporan keuangan dapat dilihat dalam daftar laporan pada software accurate, untuk melihat laporan keuangan pada akhir Februari tahun 2017, berikut langkah-langkahnya :

\author{
Penerapan \\ Sistem Informasi \\ Accurate Versi 5 \\ terhadap \\ Penyusunan \\ Laporan \\ Keuangan (Studi \\ Kasus Pada CV \\ Percetakan \\ Karya)
}

274 
Penerapan

Sistem Informasi

Accurate Versi 5

terhadap

Penyusunan

Laporan

Keuangan (Studi

Kasus Pada CV

Percetakan

Karya)

$\underline{275}$
1. Buka Tab laporan dan pilih daftar laporan

2. Pilih kategori laporan yang hendak dilihat yaitu laporan keuangan

3. Pilih detail laporan sesuai keinginan dan terdapat banyak jenis laporan yang bisa dilihat, pada umumnya adalah laporan neraca yang tersedia beberapa jenis dan laporan laba rugi.

4. Pilih "Neraca (Standar)" dan ketik tanggal laporan yang ingin dilihat, lalu klik OK

5. Untuk melihat laporan laba rugi pilih "Laba/Rugi (Standar)", ketik tanggal laporan yang ingin dilihat dan klik OK

Berikut gambar untuk menunjukkan bagaimana untuk melihat hasil laporan keuangan neraca per tanggal 28 Februari 2017 :

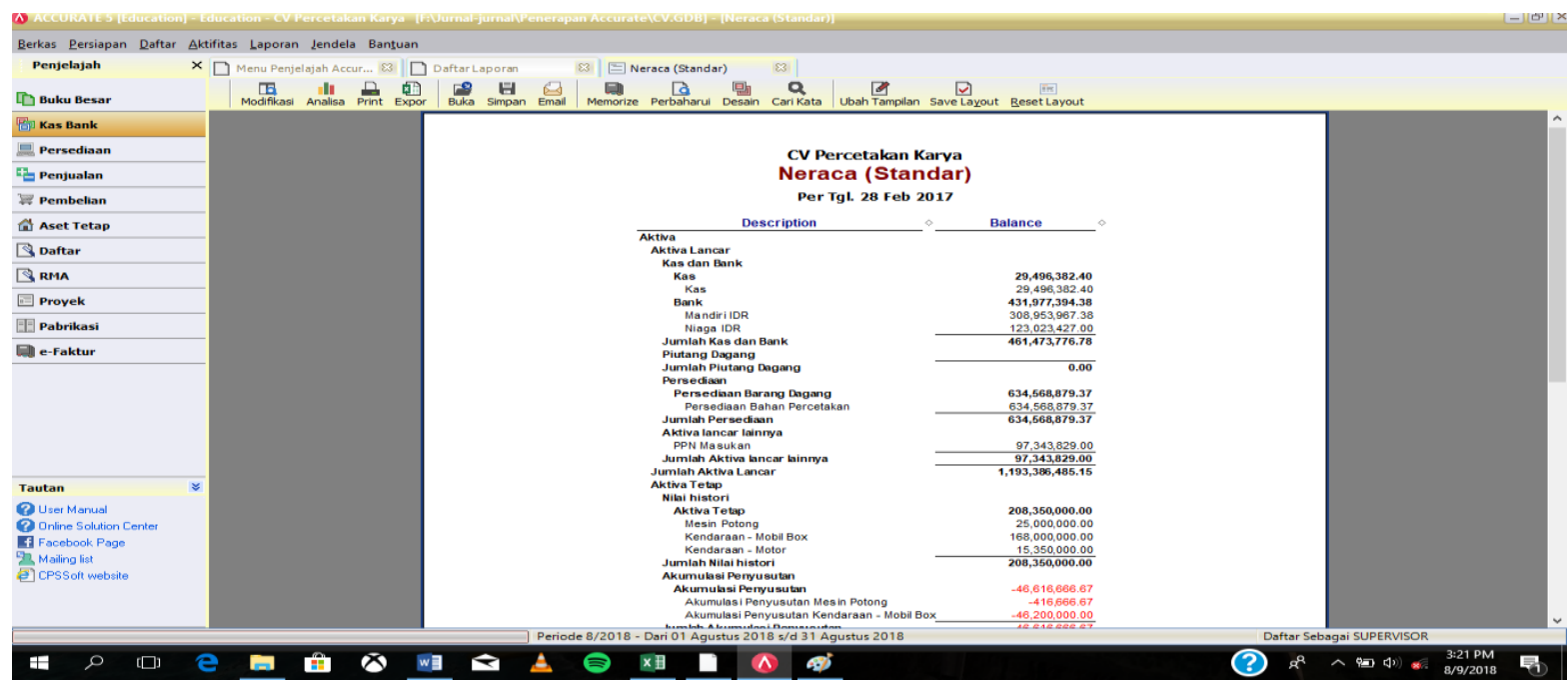

Gambar 3

Laporan Neraca

Sedangkan gambar ini untuk menunjukkan bagaimana hasil laporan keuangan laba rugi CV Percetakan Karya untuk yang berakhir tanggal 28 Feruari 2017 :

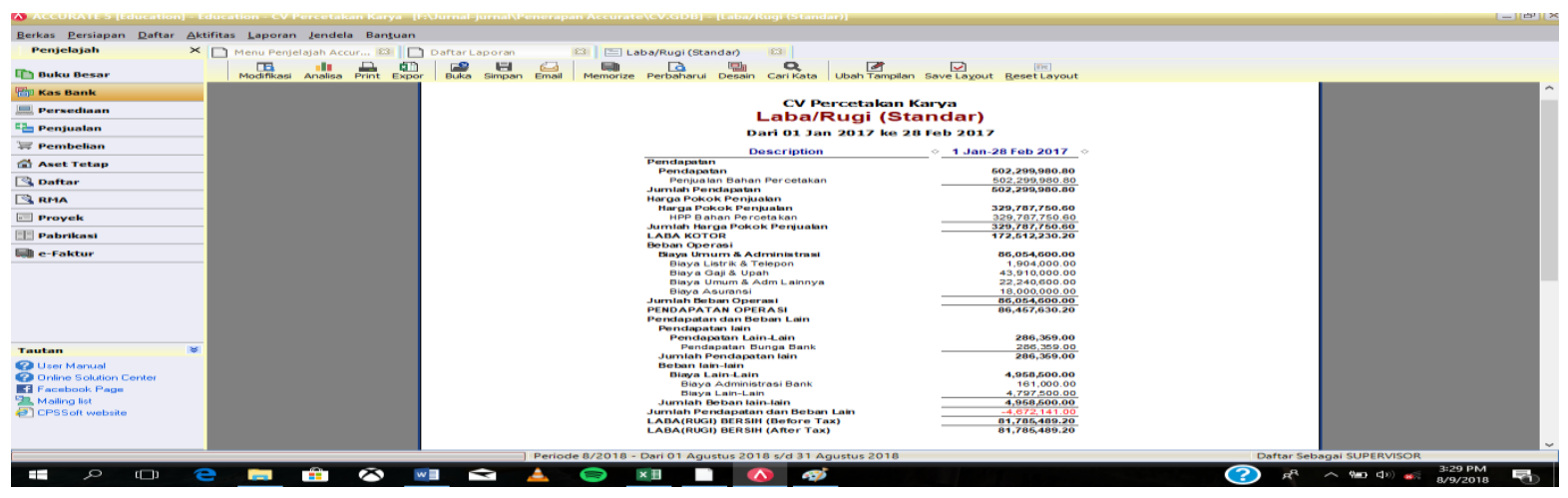

Gambar 4

Laporan Laba Rugi

Setelah proses trial entri data selama bulan Januari dan Februari tahun 2017, sebelum menerapkan penuh sistem aplikasi accurate, perusahaan melanjutkan input transaksi-transaksi yang terjadi dimulai dari bulan Maret tahun 2017 sampai Agustus tahun 2018. Sejak bulan September 2018, perusahaan melanjutkan seluruh transaksi dengan menggunakan aplikasi accurate accounting. 


\section{SIMPULAN DAN SARAN}

\section{Simpulan}

Setelah melakukan penelitian tentang penerapan sistem informasi Accurate versi 5 dalam hal penyusunan laporan keuangan perusahaan, maka dapat diambil simpulan sebagai berikut :

1. Laporan keuangan masih berupa laporan manual yaitu berbentuk laporan Excel yang terdiri dari laporan uang masuk, laporan uang keluar, laporan penyesuaian barang akhir tahun, dan laporan kas secara keseluruhan.

2. Perusahaan sudah dapat dilakukan implementasi sistem akuntansi Accurate versi 5 untuk menghasilkan beberapa laporan keuangan selama dua bulan transaksi pada bulan Januari dan Februari tahun 2017.

\section{Saran}

Berdasarkan simpulan diatas, disarankan agar pada saat menerima pesanan dan barang tersedia untuk dijual, sebaiknya dilakukan konfirmasi pesanan terlebih dahulu, baik secara lisan maupun tertulis, agar jika terjadi sesuatu pada tahap pengiriman perusahaan memiliki bukti bahwa telah mengirimkan konfirmasi pesanan kepada pelanggannya. Selain itu, pada saat melakukan pemeriksaan ketersediaan barang sebaiknya membuat kartu stok untuk control yang lebih baik terhadap persediaan.

Perusahaan belum memakai sistem terkomputerisasi, dengan demikian disarankan untuk memakai program Accurate Versi 5 yang diharapkan dapat membantu menghasilkan laporan keuangan lebih cepat dan akurat.

\section{DAFTAR PUSTAKA}

Baig, A. H. and Gururajan, R. 2011. Preliminary Study to Investigation the Determinants that Effect IS/IT Outsourcing. Journal of Information and Communication Technology Research, 1 (2), pp: 48-54.

Baridwan, Z. 1991. Sistem Akuntansi Penyusunan Prosedur dan Metode. Edisi 5, Yogyakarta, BPFE.

Bodnar, George H. \& Hopwood, William S. 1996. Sistem Informasi Akuntansi. Alih Bahasa : Amir Abadi Yusuf. Salemba Empat, Jakarta.

Char, A.K, Yasoa, R.M \& Zakiah H. 2010. Small and Medium Enteprises (SMEs) Competing in the Global Business Envirenmont: A Case of Malaysia. International Business Research, Vol. 3 No. 1, pp. 66-75.

Dewan Standar Akuntansi Keuangan. 2015. Pernyataan Standar Akuntansi Keuangan. Ikatan Akuntan Indonesia, Jakarta.

Diana, A. \& Setiawati, L. 2012. Sistem Informasi Akuntansi : Perancangan, Proses, Dan Penerapan. CV Andi Offset, Yogyakarta.

Eisenhardt, K. M. 1989. Agency Theory: An Assessment and Review. Academy of Management. The Academy of Management Review 14(1): 57.

Ghobakhloo, M., Hong, T. S., Mohammad, S. S., and Norzima, S. 2012. Strategies for Successful Information Technology Adoption in Small and Medium-sized Enterprises. Journal Information, 1 (3), pp: 36-67.

Gillespie, Cecil. 1971. Accounting Systems Procedures and Methods. Edisi 3, Prentice Hall, New Jersey.

Gulo, W. 2010. Metodolgi Penelitian. PT Grasindo, Jakarta.
Penerapan Sistem Informasi Accurate Versi 5 terhadap

Penyusunan Laporan Keuangan (Studi Kasus Pada CV

Percetakan Karya) 
Penerapan Sistem Informasi Accurate Versi 5 terhadap Penyusunan Laporan Keuangan (Studi Kasus Pada CV Percetakan Karya)

277
Hery 2014. Akuntansi Dasar 1 \& 2. PT Gramedia Widiasarana Indonesia, Jakarta.

Jensen, M. C., dan W. H. Meckling. 1976. Theory of The Firm: Managerial Behavior, Agency Costs and Ownership Structure. Journal of Financial Economics 3(4): 305360 .

Jogiyanto 2005. Analisis dan Desain Sistem Informasi: Pendekatan Terstruktur Teori dan Praktik Aplikasi Bisnis. Yogyakarta: Andi Offset.

Kementerian Koperasi dan Usaha Kecil dan Menengah Republik Indonesia. Data Perkembangan Usaha Mikro, Kecil dan Menengah. Diakses pada 7 Agustus 2017, dari http://www.depkop.go.id/berita-informasi/data-informasi/data-umkm/

Kountur, R. 2007. Metode Penelitian Untuk Penulisan Skripsi dan Tesis. Edisi 2, PPM, Jakarta.

Mulyadi, 2005. Sistem Informasi Akuntansi. Salemba Empat, Jakarta.

Mulyadi. 2001. Sistem Akuntansi. Edisi 3, Salemba Empat, Jakarta Selatan.

Narsa, I.M., Widodo, A., \& Kurnianto, S. 2012. Mengungkap Kesiapan UMKM Dalam Implementasi Standar Akuntansi Keuangan Entitas Tanpa Akuntabilitas Publik (PSAK-ETAP) Untuk Meningkatkan Akses Modal Perbankan. Majalah Ekonomi, 3.

Permana, Arieffin Dian. 2016. Penerapan Aplikasi Saiba Untuk Penyusunan Laporan Keuangan. Jurnal Akuntansi Universitas Jember. Vol 14(1).

Romney, Marshall B. \& Steinbart, Paul J. 2006. Sistem Informasi Akuntansi. Alih Bahasa: Kwary, D. A. \& Fitriasari, Dewi. Salemba Empat, Jakarta.

Sam, M.F.M., Hoshino, Yasuo., dan Tahir, M.N.H. 2012. The Adoption of Computerized Accounting System in Small Medium Enterprises in Melaka, Malaysia. International Journal of Business and Management. Vol 7(18).

Santo 2016. Manual Book Accurate 5 Accounting Software. Diakses pada 6 Agustus 2017, dari http://acisindonesia.com/manual-book-accurate-5-accounting-software/

Sarokolaei, M. A., Bishak, M. J., Rahimipoor, A., and Sahabi, E. 2012. The Effect of Information on Efficacy of the Information of Accounting System. Journal International Conference on Economics, Trade and Development, 36 (2), pp: 174177.

Soemarso, S. R. 2004. Akuntansi Suatu Pengantar Buku 1. Edisi 5, Salemba Empat, Jakarta.

Stettler, Howard F. 1974. Systems Based Independent Audits. Edisi 2, Prentice Hall, New Jersey.

Winarno, W. W. 2006. Sistem Informasi Akuntansi. UPP STIM YKPN Yogyakarta, Yogyakarta.

Yuliana, H. \& Triandi. 2013. Peranan Program Accurate Accounting Terhadap Efektivitas Pencatatan Laporan Penjualan Kredit. Jurnal Ilmiah Akuntansi Kesatuan, 1 (3), 233242. 